\title{
Effects of Closed Chain Exercise on Activities of Shoulder Girdle Muscles in 60's
}

Hye Jin Park', Tae Young Oh²

'Department of Physical Therapy, Rehabilitation Center, Seoho Hospital; ${ }^{2}$ Department of Physical Therapy, Silla University, Busan, Korea

Purpose: The purpose of this study was to compare activities of shoulder girdle muscles according to types of closed chain exercise in the sixties.

Methods: The subjects consisted of 15 persons in their sixties. Muscle activity of the pectoralis major, deltoid middle, deltoid posterior, upper trapezius, lower trapezius, and serratus anterior were measured using electromyography according to shape of the support base and angle of shoulder flexion. According to types of closed chain exercises, muscles activities were compared by paired t-test. Significance level to verify statistical significance was .05. SPSS win (ver. 22.0) program was used for statistical analysis.

Results: Muscle activities of the pectoralis major, middle deltoid, trapezius lower, and serratus anterior showed significant difference according to types of closed chain exercise $(p<0.05)$.

Conclusion: According to types of closed chain exercises of the shoulder girdle, muscle activities of the pectoralis major, deltoid middle, posterior and lower trapezius showed change of muscle activities.

Keywords: Closed chain exercise, Muscle activities, Shoulder girdle muscle

\section{서 론}

관절와상완관절(glenohumeral joint)은 구상관절로서 인체의 모든 관절 중 활동범위가 가장 크고 복잡한 부위라고 하였다. 견관절의 정상적인 기능과 안정성은 일상생활에서 중요하며, 이것은 견관절 복합체를 구성하는 여러 관절들의 상호작용과 균형에 의존한다고 하였다. ${ }^{2,3}$ 관절와상완관절은 견관절 복합 체에서 일어나는 운동의 중심이며, 어깨의 지지, 안정성을 유지 하기 위하여 뼈나 인대보다 근육에 의존하고 있다고 하였다. ${ }^{4}$

견관절 움직임의 중심적 역할을 하는 견갑골은 견관절 복합체와 관련된 근육의 길이-장력 관계를 가장 효과적이게 하며, ${ }^{5}$ 관절와상 완관절을 안정화 시키기 위해 상완골의 움직임과 함께 협력해 작용 한다고 하였다. 승모근, 견갑하근, 능형근, 소원근, 전거근 등은 견관 절을 위해 일정하면서도 효율적인 길이 장력 관계를 유지시켜줌으로 써 견관절의 안정성에 기여한다고 하였다.

견관절은 인대와 근육의 힘만으로 팔의 다양한 운동과 상지의 무 게를 지지하고 팔 운동의 조절과 안정을 제공하여 손의 많은 기능을 수행하게 하는 관절이며, 견관절 주위의 근육, 결합조직, 피부 등의
운동성과 유연성과 함께 관절 가동성을 정상적으로 유지하는 것이 매우 필요하다고 사료된다.

노화는 상. 하지의 근력 감소와 관련되며, ${ }^{8}$ 이는 관절가동범위와 근육의 유연성이 동시에 감소하게 된다고 하였다.910 Barnes 등 ${ }^{11}$ 은 연 령이 증가함에 따라 견관절의 내회전을 제외한 전방 거상, 신전, 외전, 90 도 외전에서의 내회전, 외회전과 내전상태에서의 외회전에서 견관 절의 가동범위가 감소함을 보고하였다. 연령이 증가함에 따라 65 세 이상의 건강한 노인의 $30 \%$ 정도가 견관절의 장애를 가지고 있는 것 으로 보고하고 있으며, ${ }^{12,13} 60$ 대 이상 인구에서 $60 \%$ 까지 나타난다고 하였다. ${ }^{14}$

또한 노화는 관절의 결합조직이 뼈의 선 운동이나 회전운동을 방 해하며, 이는 관절의 가동범위를 제한하기도 하고, 근육의 능동 근력 과 관절의 안정성을 제한하기도 한다고 하였다. ${ }^{14}$

최근 노인들의 체력 즉 근, 신경, 신체 구성 등에 관한 연구가 활발 하게 이루어지고 있으나 상지 보다는 하지에 관한 연구들이 많이 이 루어져 온 것이 사실이다. 이는 하지의 근력이나 기능이 균형과 낙상 에 깊이 관련이 있는 것으로 사료되나, 상지의 기능 또한 매우 중요하 다. 상지는 머리를 빗거나 지퍼를 올리는 것, 옷을 머리위로 입을 때와
Received Jul 23, 2015 Revised Aug 20, 2015

Accepted Aug 21, 2015

Corresponding author Tae Young Oh

E-mail ohtaeyoung@silla.ac.kr
Copylight (C) 2015 The Korea Society of Physical Therapy

This is an Open Access article distribute under the terms of the Creative Commons Attribution Non-commercial License (Http:// creativecommons.org/license/by-nc/3.0.) which permits unrestricted non-commercial use, distribution, and reproduction in any medium, provided the original work is properly cited. 
등뒤로 손을 뻗는 등의 기능적 동작을 수행하는데 필요하며, 노인들 의 삶의 질을 평가하는데 매우 중요한 요소가 된다. ${ }^{15}$

관절의 안정성을 증진시키는 운동에는 열린 사슬운동과 닫힌 사 슬운동이 있는데, 열린 사슬운동은 관절가동범위가 제한된 환자의 근력강화를 위해 중요한 역할을 한다고 하였다. ${ }^{16}$

닫힌 사슬운동은 사지의 원위부는 고정되어 있는 상태에서 근위 부와 원위부에서 저항을 동시에 적용할 때 일어나는 운동으로, ${ }^{17}$ 근 력강화, 지구력 증진뿐만 아니라 관절면의 기계적인 압박을 통해 여 러 근육의 협응수축을 일으키며, 관절 부위의 고유수용성 감각을 제 공하므로 관절의 동적 안정성과 자세유지를 위해 운동치료 프로그 램에서 자주 이용하고 있다고 하였다. ${ }^{18,38}$

견갑골 안정화를 위한 닫힌 사슬 운동에는 푸쉬업(push up exercise), 푸쉬업 플러스(push up plus exercise), 월 푸쉬업 플러스(wall push up exercise), 등척성 볼 운동(isometric ball exercise) 등이 있으며, ${ }^{19-21}$ 닫 힌 사슬운동이 부하 없는 열린 사슬운동보다 통증이 있거나 불안정 한 견관절 재활프로그램에 생체역학적으로 안전하고 기능적이라고 하였다.22

Weon 등 23은 전방머리자세를 중립머리자세와 비교하여 앉은 자세 로 등척성 상완굴곡을 각 $30^{\circ}, 60^{\circ}, 90^{\circ}, 120^{\circ}$ 에서 실시하였을 때 전거 근, 승모근 상부, 하부 섬유의 근활성도를 연구하였다. Hardwick 등 24 은 벽 슬라이드 운동(wall slide exercise)을 실시하였을 때 벽을 마주하 고 선 자세에서 견관절의 굴곡 $90^{\circ}, 120^{\circ}, 140^{\circ}$ 각도에서 전완을 벽에 붙인 상태로 슬라이드 운동을 실시한 후 전거근의 활성도를 다른 운 동과 비교하였다.

견관절 안정화를 위한 열린 사슬, 닫힌 사슬운동 형태에서의 근활 성도 비교, 상완 굴곡 각도에 따른 근활성도를 비교한 연구는 있었으 나 닫힌 사슬 운동에서 지지면의 변화와 함께 상완 굴곡 각도에 따른 견관절 주위근들의 근활성도를 비교하는 연구가 주로 20 대를 대상 으로 이루어졌으며, 60 세 이상의 노인을 대상으로 하는 연구는 매우 부족하였다.

이에 본 연구에서는 정상 노인들에게 견관절의 안정성에 작용하 는 근육들을 닫힌 사슬운동을 통하여 알아보고자 하였으며, 닫힌 사슬 운동의 형태에 따라 근활성도가 어떻게 변화되는지 확인하고 자 견관절 굴곡각도와 지지면에 변화를 주어 노인들의 견관절 주위 근 활성도에 미치는 영향을 알아보고자 하였다.

\section{연구방법}

\section{1. 연구대상}

본 연구는 연구 목적과 방법에 대하여 충분한 설명을 들은 후 자발적 으로 본 실험에 참여할 것을 서면 동의한 건강한 60 대 15 명 (남자: 8
명, 여자: 7명)으로 구성되었으며, 평균 59.7세, 평균 신장 $165.7 \mathrm{~cm}$, 평 균 체중 $64.93 \mathrm{~kg}$ 이며, 어깨 근육의 위축, 기형 정형외과적 혹은 신경 학적 증상을 호소하는 자는 제외하였으며 정기적으로 어깨 관련 근 력 운동을 하는 자도 제외하였다.

\section{2. 실험방법}

\section{1) 근전도}

본 연구에서는 표면 근전도(surface EMG, KEYPOINT ${ }^{\circledR}$, Medtronic, USA)를 사용하였다. 근전도 신호의 표본 추출률(Sampling rate)은 $1,024 \mathrm{~Hz}$ 로 설정하였고, 근전도의 주파수 대역폭(bandwidth)은 20$450 \mathrm{~Hz}$ 를 사용하였다.

실험 전 견갑골 안정화에 기여하는 대흥근, 중앙 삼각근, 후면 삼 각근, 상부 승모근, 하부 승모근, 전거근을 대상으로 하였으며, ${ }^{2}$ 근전 도 신호량 측정을 위해 Boettcher ${ }^{25}, \mathrm{Gawk}^{26}$ 등의 연구를 참조하여 각 근육의 전극 부착 위치를 결정하였다.

근전도 신호에 대한 피부 저항을 줄이기 위해, 측정부위의 털을 제 거 하여 알코올 솜으로 부착부위를 깨끗하게 하였다. 전극은 표면 근 전도 측정을 위한 도자를 이용하였다. 근전도 전극 부착 후 각 근육 의 신호를 점검한 후 본 실험을 실시하였다.

실험을 통해 얻어진 각 근육의 근활성도를 표준화하기 위해서 도 수근력검사 자세에서 최대 등척성 수축(Maximal voluntary isometric contraction, $\mathrm{MVIC}$ )시 각 근육의 근활성도를 측정하였다. 5 초 동안의 자료값을 root mean square (RMS)로 수집한 후 중간 3 초 간의 RMS값 을 \%MVIC로 사용하였다. MVIC 측정자세는 Kelly, ${ }^{27} \mathrm{McCabe}{ }^{28}$ 등의 연구를 참고하였다.

\section{2) 압력 생체 되먹임 장치}

본 실험에 사용된 압력 생체 되먹임 장치는 pressure biofeedback unit (Stabilizer, Chattanooga Group Inc., Hixson, USA)으로 안정화 근육들 의 재교육을 위해 물리치료사들에 의해 개발된 치료 도구이다. 치료 를 하는 동안 압력센서는 환자들에게 유용한 시각 되먹임 정보를 제 공해 준다. 경추와 요추 안정화 근육들의 재교육과 각 관절들의 안정 성 증진을 위해 자주 사용되어 진다고 하였다.29

\section{3. 실험절차}

실험 전 대상자들에게 실험에 대해 충분히 설명한 후 진행하였다. 닫 힌 사슬운동을 이용한 실험을 위해 실험대상자는 벽을 마주하고 선 자세에서 실험하였다. 닫힌 사슬운동에서 견관절 굴곡각도와 지지 면 변화에 따른 견관절 주위근 활성도를 보기 위하여 견관절 굴곡각 도는 $90^{\circ}$ 와 $135^{\circ}$ 로 구분하여 진행하였고, 지지면은 종이와 압력 생체 되먹임 장치(Stabilizer)로 구분하여 진행하였다(Figure 1). 모든 대상자 

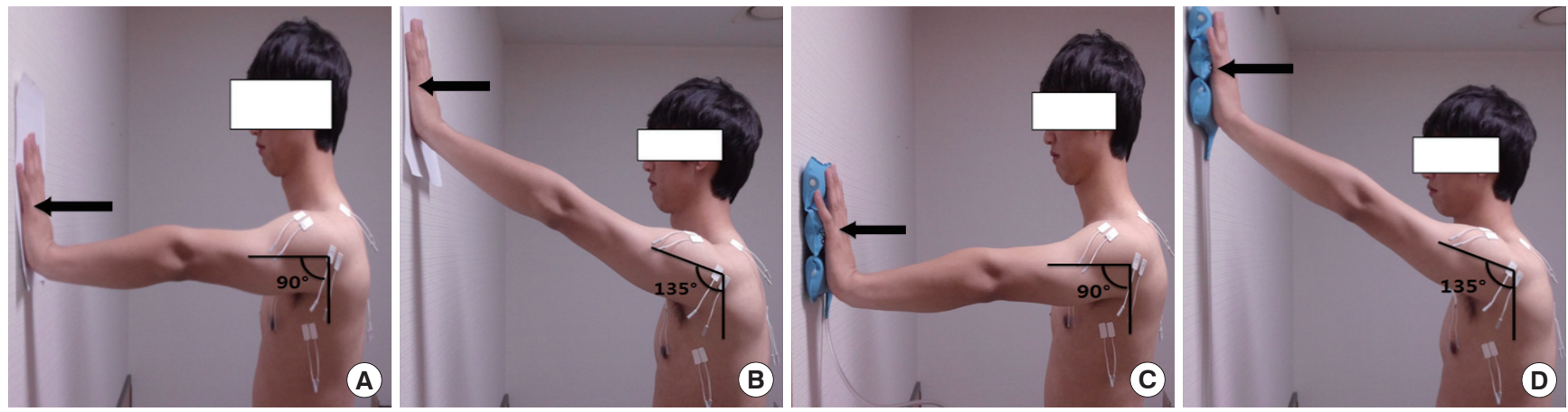

Figure 1. (A) Shoulder $90^{\circ}$ flexion on paper. (B) Shoulder $135^{\circ}$ flexion on paper. (C) Shoulder $90^{\circ}$ flexion on stabilizer. (D) Shoulder $135^{\circ}$ flexion on stabilizer.

들은 무작위순서로 운동을 실시하였다. 각각의 조건을 3 회씩 측정하 였으며, 조건 간 1 분의 휴식을 주었다. 근전도 신호는 견관절을 $90^{\circ}$ 와 $135^{\circ}$ 굴곡을 유지한 상태에서 5 초간 최대한 힘을 주어 벽을 밀면서 지 지면을 유지하도록 하여 획득하였으며, 실험절차는 다음과 같았다.

1) 대상자들은 무작위순서로 각각의 지지면에서 왼쪽 상완을 각각 $90^{\circ}$ 와 $135^{\circ}$ 굴곡하였다.

2) 종이를 이용하여 닫힌 사슬운동을 할 때에는 대상자에게 종이가 떨어지지 않게 유지하도록 하여 실험을 진행하였다.

3) 압력 생체 되먹임 장치를 이용하여 닫힌 사슬운동을 할 때에는 초 기 압력을 $20 \mathrm{mmHg}$ 로 설정한 후, 대상자에게 압력 값을 $40 \mathrm{mmHg}$ 로 유지하도록 하여 실험을 진행하였다.

\section{4. 분석방법}

바로 선 자세에서 견관절 굴곡각도와 지지면에 따른 따른 견관절 주 위근의 활성도를 비교하기 위하여 대응표본 t-검정(paired t-test)를 실 시하였다. 이 연구에서 통계학적 유의성을 검정하기 위해 유의수준 $a$ $=0.05$ 로 정하였다. 자료의 통계처리는 SPSS (Win ver. 22.0) 프로그램 을 이용하였다.

\section{결 과}

\section{1. 견관절 굴곡각도와 지지면에 따른 대흉근의 활성도 비교}

대흥근의 근활성도를 분석한 결과, 상완 $135^{\circ}$ 굴곡상태에서 지지면 변화에는 근활성도에 유의한 차이가 있었으며 $(\mathrm{p}<0.05)$, 종이 지지면 에서 상완 굴곡각도 변화에 따라 근활성도에 유의한 차이가 있었다 $(\mathrm{p}<0.05)($ Table 1$)$.

\section{2. 견관절 굴곡각도와 지지면에 따른 중앙 삼각근의 활성도 비교} 중앙삼각근은 상완 $90^{\circ}, 135^{\circ}$ 굴곡상태에서 지지면 변화에 따라 근활 성도에 유의한 차이가 있었다 $(\mathrm{p}<0.05)$ (Table 1).

\section{3. 견관절 굴곡각도와 지지면에 따른 하부승모근의 활성도 비교} 하부 승모근은 압력 생체 되먹임 장치 지지면에서 상완 굴곡 상태에 따라 유의한차이가 나타났다 $(\mathrm{p}<0.05)$ (Table 1$)$.

\section{4. 견관절 굴곡각도와 지지면에 따른 전거근의 활성도 비교} 전거근은 상완 $90^{\circ}$ 굴곡 상태에서 지지면 변화에 따라 근활성도에 유 의한차이가 있었다 $(\mathrm{p}<0.05)$ (Table 1).

\section{고 찰}

본 연구에서는 60 세 이상 노인들을 대상으로 닫힌사슬 운동형태와 견관절의 굴곡각도를 변화시켜 견관절 주위의 활성화되는 근육의 변화를 확인하고자 하였다.

Davies 등 ${ }^{4}$ 의 견관절 복합체의 신경근 재활에 관한 연구에서, 닫힌 사슬 자세에서의 견관절 강화운동은 관절낭의 부하를 줄여주고 역 동적인 안정화 구조의 동시수축을 촉진시킨다고 하였다.

Khademi Kalantari ${ }^{35}$ 의 연구에서는 20 대 대상자에게 지지면의 변화 에 따라 상부 및 하부 승모근, 전거근, 이두근 장두, 후면 삼각근, 대원 근의 활성도를 근전도로 측정한 결과 엎드린 자세에서 워블 보드 (wobble board)와 스위스볼(swiss ball) 작은 공 등을 이용한 불안정한 지지면의 닫힌 사슬운동이 안정된 지지면의 닫힌 사슬운동과 비교 하였을 때 근 활성도를 증가시키지 못한다고 하였다.

본 연구에서는 60 대 대상자에게 바로 선 자세에서 견관절 $90^{\circ}$ 굴곡 상태로 압력 생체 되먹임 장치를 지지하였을 때 대흥근, 중앙삼각근 에서 근 활성도가 의미 있게 증가하였다. 상부 승모근은 견관절 굴곡 각도와 상관없이 압력 생체 되먹임 장치보다 종이를 지지하였을 때 근 활성도가 의미있게 증가한 것을 볼 수 있었다.

이는 Khademi Kalantari의 연구에서 실시한 엎드린 자세는 견관절 $90^{\circ}$ 굴곡 상태에서 체중지지를 하는 상태로 볼 수 있으며, 본 연구에 서는 선 자세에서 견관절 90 굴곡 상태에서 불안정한 압력 생체 되먹 
Table 1. Comparison of muscle activities of each muscles according angle and surface

(Unit: \%MVIC)

\begin{tabular}{|c|c|c|c|c|c|}
\hline Muscle & Angle & Paper & Stabilizer & $\mathrm{t}$ & $\mathrm{p}$ \\
\hline \multirow[t]{4}{*}{ Pectoralis major } & Shoulder $90^{\circ}$ & $35.73 \pm 19.55^{a}$ & $43.23 \pm 24.19$ & -1.203 & 0.249 \\
\hline & Shoulder $135^{\circ}$ & $27.33 \pm 17.95$ & $42.49 \pm 22.28$ & -4.452 & 0.001 \\
\hline & $\mathrm{t}$ & 2.477 & 0.109 & & \\
\hline & $\mathrm{p}$ & 0.027 & 0.915 & & \\
\hline \multirow[t]{4}{*}{ Deltoid middle } & Shoulder $90^{\circ}$ & $25.55 \pm 11.19^{a}$ & $55.27 \pm 20.19$ & -6.732 & 0.000 \\
\hline & Shoulder $135^{\circ}$ & $25.51 \pm 10.64$ & $63.50 \pm 19.77$ & -8.536 & 0.000 \\
\hline & $\mathrm{t}$ & 0.049 & -1.961 & & \\
\hline & $\mathrm{p}$ & 0.962 & 0.070 & & \\
\hline \multirow[t]{4}{*}{ Deltoid posterior } & Shoulder $90^{\circ}$ & $16.72 \pm 20.43^{a}$ & $15.84 \pm 11.15$ & 0.251 & 0.805 \\
\hline & Shoulder $135^{\circ}$ & $17.30 \pm 17.41$ & $13.77 \pm 14.49$ & 0.749 & 0.466 \\
\hline & t & -0.399 & 0.574 & & \\
\hline & $p$ & 0.696 & 0.575 & & \\
\hline \multirow[t]{4}{*}{ Trapezius upper } & Shoulder $90^{\circ}$ & $27.53 \pm 15.55^{a}$ & $24.38 \pm 16.80$ & 0.865 & 0.402 \\
\hline & Shoulder $135^{\circ}$ & $25.94 \pm 14.65$ & $21.16 \pm 17.30$ & 0.948 & 0.359 \\
\hline & $\mathrm{t}$ & 0.978 & 0.743 & & \\
\hline & $\mathrm{p}$ & 0.345 & 0.470 & & \\
\hline \multirow[t]{4}{*}{ Trapezius lower } & Shoulder $90^{\circ}$ & $28.03 \pm 21.35^{a}$ & $27.25 \pm 17.26$ & 0.136 & 0.894 \\
\hline & Shoulder $135^{\circ}$ & $25.11 \pm 15.46$ & $17.42 \pm 11.43$ & 2.143 & 0.050 \\
\hline & $\mathrm{t}$ & 0.999 & 2.273 & & \\
\hline & $\mathrm{p}$ & 0.335 & 0.039 & & \\
\hline \multirow[t]{4}{*}{ Serratus anterior } & Shoulder $90^{\circ}$ & $56.35 \pm 26.10^{a}$ & $37.10 \pm 21.61$ & 2.123 & 0.052 \\
\hline & Shoulder $135^{\circ}$ & $47.62 \pm 19.37$ & $37.29 \pm 22.90$ & 1.266 & 0.226 \\
\hline & $\mathrm{t}$ & 3.204 & -0.037 & & \\
\hline & $\mathrm{p}$ & 0.006 & 0.971 & & \\
\hline
\end{tabular}

${ }^{a}$ Mean \pm SD.

임 장치를 지지하였을 때 대흥근, 중앙 삼각근에서 활성도가 높았다 는 결과와 서로 상반된 결과를 보이고 있으며, 이에 반해 상부 승모근 은 견관절 각도와 상관없이 벽에 위치한 안정된 종이를 선 자세에서 밀 때 높은 활성도를 나타낸 것은 일부 일치하는 결과라고 할 수 있 을 것이다.

대흥근의 쇄골부분은 쇄골의 흥골쪽에서 기시하여 상완골의 대 결절능에 부착되어 견관절을 굴곡시키고 수평내전 시킨다. 흉늑골 부분은 흥골의 전면, 6-7번째 늑골, 연골 그리고 외복사근 건막에서 기시하여 상완골의 대결절능으로 부착되어 견갑골을 하강시킨다고 하였다. ${ }^{30}$

삼각근은 쇄골의 외측, 견봉, 견갑극에서 기시하여 상완골 삼각근 조면에 정지하는 근육으로서, 견관절 메커니즘의 가장 큰 생리학적 단면적 근육이며, 상완 관절의 외전에서 가장 중요한 역할을 한다고 하였다. ${ }^{30}$ 외전을 하는 동안 중앙삼각근은 가장 활성화된다. 전면삼각 근은 상완의 굴곡에 영향을 미치며, 후면삼각근은 신전에 영향을 미 친다. 상완골의 축회전과 함께 결합된 측면 회전을 통해서 후면삼각 근의 모멘트 팔은 더 작아진다. 후면삼각근은 전방굴곡 $90^{\circ}$ 이상이 되면 큰 모멘트 팔이 되며, 활성화된다. 증가하는 후면삼각근의 활동
으로 인해 중앙삼각근은 전방굴곡 $60^{\circ}$ 에서 가장 크게 활성화된다고 하였다. ${ }^{5}$

Lehman 등른 10 명의 젊은 남성을 대상으로 한 연구에서 안정한 지지면과 불안정한 지지면에서 푸쉬업(push up)과 푸쉬업 플러스 (push up plus) 운동을 한 후 상부 승모근, 하부 승모근, 전거근, 상완 이 두근 등의 모든 근육에서 지지면 안정에 따른 근활성도는 통계적으 로 유의한 차이가 없었으나, 지지면 안정도와 관계없이 손과 발의 위 치 변화에서는 상부 승모근과 전거근의 활성도가 유의한 차이가 있 었다고 보고하였다.

본 연구에서는 벽에 위치한 종이를 밀 때를 안정된 지지면, 생체 압 력 되먹임 장치를 불안정한 지지면으로 볼 때, 견관절을 $90^{\circ}$ 로 굴곡과 불안정한 면에서의 닫힌 사슬 운동이 대흥근과 중앙삼각근의 근활 성도를 높였던 것으로 나타나 일부 일치하는 면이 있으며, 상부 승모 근의 근활성도가 지지면에 상관없이 견관절 각도에 따라 유의하게 높게 나타나 역시 일부 일치하는 면이 있는 것으로 사료된다.

이는 견관절 안정성에 관여하는 근육들 중 지지면의 안정성에 따 라서는 근활성도의 차이가 크게 나타나지 않지만, 견관절의 굴곡 각 도의 변화에 따라서는 근활성도의 차이가 크게 나타난다는 것을 의 
미하고 있으며, 이는 건강한 20 대와 건강한 60 대의 결과가 전혀 상반 되지 않는 것으로 사료된다.

$\mathrm{Moon}^{36}$ 의 연구에서 건강한 성인 남성 16 명 (평균연령 20.7세)을 대 상으로 열린 사슬운동과 닫힌 사슬운동에서 상완 굴곡각도에 따른 상부 승모근, 대흥근, 전거근 등의 활성도를 견관절 $70^{\circ}, 90^{\circ}, 110^{\circ}$ 에서 측정한 결과 상부 승모근, 대흥근의 근 활성도는 견관절 굴곡각도와 운동형태에 따라 유의한 차이가 없었으나, 전거근의 근활성도는 굴 곡각도의 변화에 따라 유의한 차이가 있었다고 보고하였다.

$\mathrm{Moon}^{36}$ 의 연구는 선 자세에서 닫힌 사슬 운동을 위하여 벽에 기계 식 저울을 밀도록 하였으며 열린 사슬 운동을 위해서는 뒤쪽 벽에 있 는 밴드를 앞으로 팔을 뻗으면서 내밀도록 하여 본 연구에서 이용한 방법과는 다소 다른 방법을 선택하였다.

본 연구에서는 상완을 종이에 지지하여 굴곡각도가 증가함에 따 라 대흥근, 전거근의 근활성도는 유의한 차이를 나타냈다. 압력 생체 되먹임 장치에 지지하여 굴곡각도가 증가함에 따라 하부 승모근의 근 활성도는 유의한 차이를 나타냈으며, 중앙삼각근과 전거근의 근활성 도가 통계적으로 유의하지는 않았지만 증가하는 것을 볼수 있었다.

$\mathrm{Moon}^{36}$ 연구 결과에서 전거근의 결과는 견관절 굴곡 각도에 따라 변화를 보여 준 본 연구와 일부 일치하는 면을 보이고 있으며, 상부 승모근의 결과는 서로 다른 양상을 보이는 것으로 나타났다.

승모근의 일반적인 기능은 상부 승모근의 견갑골 상방회전과 거 상, 중간 승모근의 후인, 하부 승모근의 상방회전과 하강을 포함한다. 또한 하부 승모근의 내측하부 방향의 섬유들은 팔을 굴곡시키는 동 안에 견갑골의 외회전과 후방경사에 기여한다. ${ }^{31}$ 상부 승모근의 높은 활성도와 관련된 활동은 숄더 쉬러그(shoulder shrug), 엎드린 자세에 서 팔 끌어올리기(prone rowing), 엎드린 자세에서 내·외 회전이 동반 된 외전에서 $90^{\circ}$ 와 $135^{\circ}$ 수평외전이다.

하부 승모근의 높은 활성도와 관련된 활동은 엎드린 자세에서 팔 끌어올리기(prone rowing), 엎드린 자세에서 내·외 회전이 동반된 외 전에서 $90^{\circ}$ 와 $135^{\circ}$ 수평외전, $90^{\circ}$ 외전에서 외회전이다. 하부 승모근의 활성도는 $90^{\circ}$ 이하에서의 scaption, 외전, 굴곡에서 점차적으로 낮아 지는 경향이 있으며, $90^{\circ}$ 에서 $180^{\circ}$ 까지 기하급수적으로 증가한다고 하였다. ${ }^{32}$

전거근은 소흥근과 함께 견갑골을 외전 시키며, 상. 하부 승모근과 함께 견갑골을 상방 회전 시킨다. 전거근은 상지를 굴곡시키는 동안 에 상방회전, 후방경사, 외회전 같은 정상적인 견갑골 움직임의 모든 요소에 기여하는 중요한 근육이다. 또한 견갑골의 내회전과 전방경 사를 막기 위하여 견갑골의 내측면과 하각을 안정화시키는데 도움 을 준다고 하였다. ${ }^{31,33}$

$\mathrm{Jang}^{37}$ 의 연구에서는 20 대 15 명의 남자를 대상으로 열린 사슬운동 과 닫힌 사슬운동을 하는 동안 상완을 $0^{\circ}, 45^{\circ}, 90^{\circ}, 135^{\circ}$ 로 굴곡한 상
태에서 외회전을 하여 극하근, 전면삼각근, 중앙삼각근, 후면삼각근, 상부 승모근, 원회내근의 근활성도를 비교한 결과 전면삼각근, 중앙 삼각근, 상부 승모근, 원회내근은 운동방법과 상완 굴곡각도의 변화 에 따라 유의한 차이가 나타났으나, 후면삼각근은 운동방법과 상완 굴곡각도의 변화에 따른 유의한 차이가 나타나지 않았다고 보고하 였다.

본 연구의 결과와 비교하였을 때 운동방법과 견관절 굴곡각도에 따라 일부 일치하는 결과를 나타내었다.

$\mathrm{Kim}$ 등 ${ }^{39}$ 은 뇌졸중 환자 30 명을 대상으로 압력 생체 되먹임 장치 를 이용한 어깨 안정화 운동이 대상자들의 견갑골 거리, 동적 균형 등 에서 유의한 개선을 보였다고 하여 뇌졸중 환자들의 견갑대 안정화 를 위해 안정화 운동, 즉 닫힌 사슬 운동이 필요할 것으로 사료된다.

결론적으로 본 연구는 60 대의 닫힌 사슬운동형태가 견관절 주위 근 활성도에 미치는 영향에 대해 알아보았으며, 대흥근, 중앙삼각근, 하부 승모근, 전거근은 지지면의 변화 보다는 견관절 따라 더 큰 근활 성도의 차이가 있었다고 할수 있다.

따라서 본 연구를 통하여 젊은 대상자가 아닌 60 대 이상의 노인들 에게 견관절 주위근의 안정화를 위하여 견관절 굴곡각도, 지지면 상 태 등을 변화 시킴으로써 다양한 근활성도의 변화를 확인할 수 있었 으며, 이는 견관절 안정화 운동, 편마비 환자의 견관절 안정성 향상 등을 위해 임상적으로 널리 이용될 수 있는 기전을 확인한 결과로서 그 의미가 크다고 할 수 있을 것이다. 또한 선행연구가 거의 20대 대상 자를 연구한 결과이므로 향후 같은 실험 방법을 통하여 20대와 60대 의 견관절 안정성에 관여하는 근육들의 활성도를 비교하는 연구가 필요할 것으로 사료된다.

본 연구의 제한점은 일반인을 대상으로 실험을 하였으므로 다양 한 환자에게 일반화하기에는 무리가 있을 것으로 사료되며, 노화에 따른 근활성도의 차이를 임상적으로 해결할 수 있는 다양한 관리가 이루어져야 할 것으로 사료된다.

\section{REFERENCES}

1. Curl LA, Warren RF. Glenohumeral joint stability. Selective cutting studies on the static capsular restraints. Clin Orthop Relat Res. 1996;330:5465.

2. Decker MJ, Hintermeister RA, Faber KJ et al. Serratus anterior muscle activity during selected rehabilitation exercise. Am J Sports Med. 1999;27(6):784-91.

3. Hess SA. Functional stability of the glenohumeral joint. Man Ther. 2000; 5(2):63-71.

4. James AP, Carl D. Mechanical shoulder disorder: Perspectives in functional anatomy. Philadelphia, Elsevier Saunders. 2004;91-125.

5. Van del Helm FC. Analysis of the kinematics and dynamic behavior of the shoulder mechanism. J Biomech. 1994;27(5):527-50. 
6. Matsen II FA, Harryman II DT, Sidles JA. Mechanics of glenohumeral instability. Clin J Sport Med. 1991;10:783-8.

7. Wilk KE, Arrigo CA, Andrews JR. Current concepts: the stabilizing structures of the glenohumeral joint. J Orthop Sports Phys Ther. 1997;25:364-79.

8. Asmussen E, Heeboll-Nielsen K. Isometric muscle strength in relation to age in men and women. Ergonomics. 1962;5:167-9.

9. Gertsen JW, Ager C, Anderson K et al. Relation of muscle strength and range of motion to activities of daily living. Arch Phys Med Rehabil. 1970;51(3):137-42.

10. Gehlsen GM, Whaley MH. Falls in the elderly: balance, strength, and flexibility. Arch Phys Med Rehabil. 1990;71(10):739-41.

11. Barnes CJ, Van Steyn SJ, Fischer RA. The effects of age, sex, and shoulder dominance on range of motion of the shoulder. J Shoulder Elbow Surg. 2001;10(3):242-6.

12. Matsen III, FA, Lippitt SB, Sidles JA et al. Practical evaluation and management of the shoulder. Philaelphia: WB Saunders, 1994;5-9.

13. Milgrom C, Schaffler M, Gilbert S et al. Rotator-cuff changes in asymptomatic adults: The effect of age, hand dominance and gender. J Bone Joint Surg. 1995;77(2):296-8.

14. Hijioka A, Suzuki K, Nakamura T et al. Degenerative change and rotator cuff tears: an anatomical study in 160 shoulders of 80 cadavers, Arch Orthop Trauma Surg. 1993;112: 61-4.

15. Kim CK, Lee WY, Bae YJ et al. A change of the upper and lower extremity muscle function in the elderly. Exercise Science. 2000;9(2):405-15.

16. Jang JW. The change of muscle activation in quadriceps femoris muscle during taking open kinetic chain exercise and closed kinetic chain exercise : on the subject of soccer players. Korea University. Dissertation of Master's Degree. 2003.

17. Karandikar N, Vargas OO. Kinetic chains: a review of the concept and its clinical applications. PM\&R. 2011;3(8):739-45.

18. Ellenbecker TS, Davies GJ. Closed kinetic chain exercise: a comprehensive guide to multiple joint exercise. Illinois, Human Kinetics, 2001;115.

19. Ludewig PM, Hoff MS, Osowski EE et al. Relative balance of serratus anterior and upper trapezius muscle activity during push-up exercises. Am J Sports Med. 2004;32(2):484-93.

20. Liebenson C. Self-management of shoulder disorders- part3: Treatment. J Body Mov Ther. 2006;10: 65-70.

21. Lehman GJ, Gilas D, Atel U. An unstable support surface does not increase scapulthoracic stabilizing muscle activity durineg push up and push up plus exercise. Man Ther. 2008;13(6):500-6.

22. Steindler A. A kinesiology of the human body under normal and pathological conditions. Illinois, Springfield, 1995.

23. Weon JH, Oh JS, Cynn HS et al. Influence of forward head posture on scapula upward rotators during isometric shoulder flexion. J Bodyw Mov Ther. 2010;14(4):367-74.

24. Hardwick DH, Beebe JA, McDonnell MK et al. A comparison of serra- tus anterior muscle activation during wall slide exercise and other traditional exercises. J Orthop Sports Phys Ther. 2006;36(12):903-10.

25. Boettcher CE, Ginn KA, Cathers I. Standard maximum isometric voluntary contraction tests for normalizing shoulder muscle EMG. J Orthop Res. 2008;26(12):1591-7.

26. Gwak DH. Evaluation and classification of shoulder joint range of motion based on electromyography. Aju University. Dissertation of Master's Degree. 2013.

27. Kelly BT, Kadrmas WR, Kirkendall DT et al. Optimal normalization tests for shoulder muscle activation: an electromyographic study. J Orthop Res. 1996;14(4):647-53.

28. McCabe RA, Orishimo KF, McHugh MP et al. Surface electromygraphic analysis of the lower trapezius muscle during exercises performed below ninety degrees of shoulder elevation in healthy subjects. N Am J Sports Phys Ther. 2007;2(1):34.

29. Cairns MC, Harrison K, Wright C. Pressure Biofeedback: A useful tool in the quantification of abdominal muscular dysfunction? Physiotherapy. 2000;86(3):127-38.

30. Halder AM, Itoi E. An KN. Anatomy and biomechanics of the shoulder. Orthop Clin North Am. 2000;31(2):159-76.

31. Ludewig PM, Cook TM, Nawoczenski DA. Three-dimensional scapular orientation and muscle activity at selected positions of humeral elevation. J Orthop Sports Phys Ther. 1996;24(2):57-65.

32. Andrews JR, Wilk KE, Reinold MM. The athlete's shoulder. Elsevier Health Sciences. 2008;603-25.

33. McClure PW, Michener LA, Sennett BJ et al. Direct 3-dimensional measurement of scapular kinematics during dynamic movements in vivo. J Shoulder Elbow Surg. 2001;10(3):269-77.

34. Davies GJ, Dickoff-Hoffman S. Neuromuscular testing and rehabilitation of the shoulder complex. J Orthop Sports Phys Ther. 1993;18(2): 449-58.

35. Khademi Kalantari K \& Berenji Ardestani S. The effect of base of support stability on shoulder muscle activity during closed kinematic chain exercises. J Bodyw Mov Ther. 2014;18(2): 233-8.

36. Moon SJ, Kim TH, Roh JS. A comparison of the serratus anterior muscle activity according to the shoulder flexion angles in a closed kinetic chain exercise and an open kinetic chain exercise. J of Korean Soc of Phys Med. 2013;8(3):369-78.

37. Jang JH. The effects of infraspinatus muscle activity on humeral external rotation exercise in open and closed kinetic chain. Daegu University. Dissertation of Master's Degree. 2011.

38. Lee KY, Shin WS. The effects of closed kinetic and open kinetic chain exercise using knee reposition sense in chronic stroke patients. J Kor Soc Phys Ther. 2014;26(3):182-90.

39. Kim GH, Choe HS, Lee HI et al. The effects of scapular stabilization exercising on dynamic standing balance in stroke patients. J Kor Soc Phys Ther. 2014;26(1):15-20. 